\title{
Problem Solving Heuristics and Mathematical Abilities of Heterogeneous Learners
}

\author{
Rose R. Andrade ${ }^{1, *}$, Erminda C. Fortes², Rina A. Mabilangan ${ }^{3}$ \\ ${ }^{1}$ College of Teacher Education, Laguna State Polytechnic University, San Pablo City Campus, Philippines \\ ${ }^{2}$ College of Graduate Studies and Teacher Education Research, Philippine Normal University, Philippines \\ ${ }^{3}$ UP Rural High School, College of Arts and Sciences, University of the Philippines, Los Baños, Philippines
}

Received June 17, 2020; Revised August 13, 2020; Accepted August 25, 2020

\section{Cite This Paper in the following Citation Styles}

(a): [1] Rose R. Andrade, Erminda C. Fortes, Rina A. Mabilangan, "Problem Solving Heuristics and Mathematical Abilities of Heterogeneous Learners," Universal Journal of Educational Research, Vol. 8, No. 11, pp. 5114-5126, 2020. DOI: 10.13189/ujer.2020.081111.

(b): Rose R. Andrade, Erminda C. Fortes, Rina A. Mabilangan (2020). Problem Solving Heuristics and Mathematical Abilities of Heterogeneous Learners. Universal Journal of Educational Research, 8(11), 5114-5126. DOI: 10.13189/ujer.2020.081111.

Copyright $\mathrm{C} 2020$ by authors, all rights reserved. Authors agree that this article remains permanently open access under the terms of the Creative Commons Attribution License 4.0 International License

\begin{abstract}
Descriptive design was utilized to identify the problem-solving heuristics and mathematical abilities of students in solving non-routine problems in terms of conceptual understanding, procedural knowledge, and problem-solving skill. Both quantitative and qualitative data were gathered from students' mathematical solutions, journals, and interviews. Six non-routine problems were given to thirty Grade 10 students. Each level of mathematical achievement includes ten students who were randomly selected using their averages in the first two quarters. "Compute or Simplify" and "Model or Diagram" were the usual strategies employed by the Proficient respondents. On the other hand, Compute or Simplify is the most frequent strategy used by Apprentice Problem Solvers. The first strategy includes straightforward application of rules in mathematics, correctly sequencing the operations and using other mathematical procedures, while the second includes the use of concrete representations and figures, acting out and formulation of algebraic statements. All the strategies were considered in solving the six non-routine problems. Most students under the three levels solved the problem by combining two or more strategies in getting the answer. Three students who belong to above-average mathematical achievement are considered proficient problem solvers while twenty-seven students who belong to average and below average are regarded as Apprentice Problem Solvers. No student among the thirty was considered Novice. Students performed best in conceptual understanding and least in
\end{abstract}

problem- solving skills. The results revealed that there are no significant differences in the levels of each of the three components of mathematical abilities of students when they are grouped according to mathematical achievement.

Keywords Problem-solving Heuristics, Non-routine Problems, Mathematical Abilities, Conceptual Understanding, Procedural Knowledge, Problem-solving Skill

\section{Introduction}

In this fast-changing world, preparing students to possess the necessary skills needed for the future workforce has been the focus of the education system all over the world. According to the World Economic Forum [1], complex problem-solving is the top skill needed for employment by 2020 . With all the changes individuals face every day, being able to use logical, critical and creative thinking to address a wide range of problems could be more important than merely gaining knowledge [2]. Hence, the development of this skill is urgent to meet the speedy changes of this digital era in which students in the future would look for a solution to unknown problems [3]. Mathematics learning plays a huge role in enhancing problem-solving skills through highly engaging mental processes and tasks [4]. Mathematics educators are one in saying that problem-solving skill is an ability that is 
essential to knowledge and hence is something that needs to be transferred from one generation to another. Thus, deviation from rote learning to problem-solving in mathematics is very urgent for human survival [5].

Problem Solving is considered a 21st-century skill that students need to master [6]. In the top-performing countries in PISA 2012 such as China, Singapore, Korea, and Japan, problem-solving is perceived as the core of mathematics education [7]. Likewise, the Philippines recognized its significance making this skill as one of the twin goals of mathematics education. However, despite the efforts of the Philippine education system, Filipino students' level of mathematical performance in international assessment deteriorates as evident in the recent PISA results in 2018. The results revealed that the Philippines scored 353 in Mathematics which is below the average of participating OECD countries [8-10]. Since most of the items in Mathematics subtest involve application problem, it reveals the unsatisfactory performance of the students in solving word problems. One reason that could be attributed to this is the limited exposure to non-routine problems [11].

Non-routine problems are problems that cannot be solved by just using a rule-based implementation [12]. It fosters the understanding that mathematics is a creative endeavor by employing various problem-solving strategies and heuristics. This is in line with Polya's belief that non-routine problems must be utilized for the students as a means of developing their mathematical thinking and problem solving for daily living. Moreover, numerous pieces of literature have acknowledged that these are the most suitable problems that could hone the reasoning skill of the students which is indispensable in coping with real-life problems $[2,13,14]$. Likewise, Webb [15] even pointed out that engaging learners into numerous cognitive processes augment their problem-solving abilities and understanding. Mathematics problem solving through non-routine problems plays a vital role in inculcating higher-order thinking skill that leads to the development of thinking and reasoning skills [16]. Besides, non-routine problems demand flexibility; it requires the knowledge of various problem-solving heuristics and strategies [17]. Exposing all students to non-routine problems is necessary as it could address the demands of the new workplace in which the critical and creative thinking are intensified (OECD, 2010). Suffice it to state that mathematical abilities and heuristics must be investigated and strengthened as they are linked to problem-solving [18].

Several studies have been conducted in the Philippines to identify the problem-solving heuristics and problem-solving abilities of the students in solving non-routine problems $[12,19,20]$. However, the respondents of the aforementioned studies are high performing students belonging to institutions with a high standard of admission. This would fill the gap by conducting the same study to heterogeneous learners. In this way, the non-routine problem-solving mathematical abilities of the said respondents would be analyzed and described. In addition, teachers would also be enlightened that non-routine problems are not intelligence-sensitive. Furthermore, this would help the teachers to identify the problem-solving strategies of diverse learners, gearing them to adjust and create more varied teaching styles for the development of the problem-solving mathematical abilities of the students.

\section{Framework of the Study}

In Theory of Constructivism, knowledge is actively constructed by assimilating new information and adjusting one's own mental models to accommodate new information. Teacher's task is to provide learners cognitive processes that would help them discover and reflect new learning. Non-routine problem solving can address this kind of learning. To see the maximum benefit, teachers should engage the learners in these kinds of problems.

The National Assessment of Educational Progress (NAEP) identifies conceptual understanding, procedural knowledge and problem-solving skill as mathematical abilities and considered as important in solving non routine problems [21-23].

1. Conceptual Understanding includes the ability to decipher the problem and choose suitable information to apply and complete the solution. Evidences of this component are shown when absorbing concepts in a coherent whole, connecting the problem situation to the entire solution that is presented in a logical manner.

2. Procedural Knowledge is the ability of the students to select and apply the most suitable strategy to a particular solution in an accurate, efficient and flexible way. Evidences of such are expressed in terms of the students' ability to verify, justify and modify procedures to be able to come up with the solution in a specific problem.

3. Problem-solving Skills and Strategies is the use of different strategies in a solution. To arrive at the correct solution in a given problem, students should exhibit creativity and flexibility in reasoning.

Using a heuristics approach to problem-solving helps the students understand the problem more thoroughly. It gives them confidence and ability to solve the problem successfully. To Polya [24], strategies or heuristics are procedures used to discover possible answers to a problem that do not necessarily guarantee that the student will arrive at the correct solution.

Polya [24] also details four important steps that can be used to understand the problems more easily. These steps are understanding the problem, devising a plan for the solution, implementing the plan and looking back at the solutions [25]. However, Krulik and Rudnick [26] identified five stages that constitute the heuristic process, namely read and think, explore and plan, select a strategy, find an answer, and reflect and extend. 
Krulik and Rudnick [26] stressed eight strategies that are applicable to mathematical problem-solving at the secondary level. These are: (1) Computing or Simplifying $(\mathrm{C} / \mathrm{S})$ - the straightforward application of rules in mathematics, correctly sequencing the operations, and using other mathematical procedures. (2) Using a Formula (F) - replacing a formula with the given values or choosing the correct formula that may be used. (3) Making a model or Diagram (M/D) - using objects, drawings or sketches, modeling through actions, or translating the problem situation into an algebraic statement. (4) Using a Tabular/Graphical Representation or Listing (TGRL) presenting the information in a table, chart, graph, or listing the possibilities. (5) Guessing, Checking, and Revising (GCR) - doing and checking some trials and modifying errors if necessary. (6) Simplifying the Situation (SS) rewording the problem, using smaller values, using a more common problem situation, partitioning the problem into simpler problem situations, or working toward the back or from the final situation to the initial one. (7) Eliminating (E) - getting rid of possible solutions based on the given data or eliminating some answers that are perceived to be incorrect. (8) Looking for Patterns (LP) - finding general characteristics of the given data and applying these attributes to future cases or situations. The foregoing discussions are depicted in Figure 1.

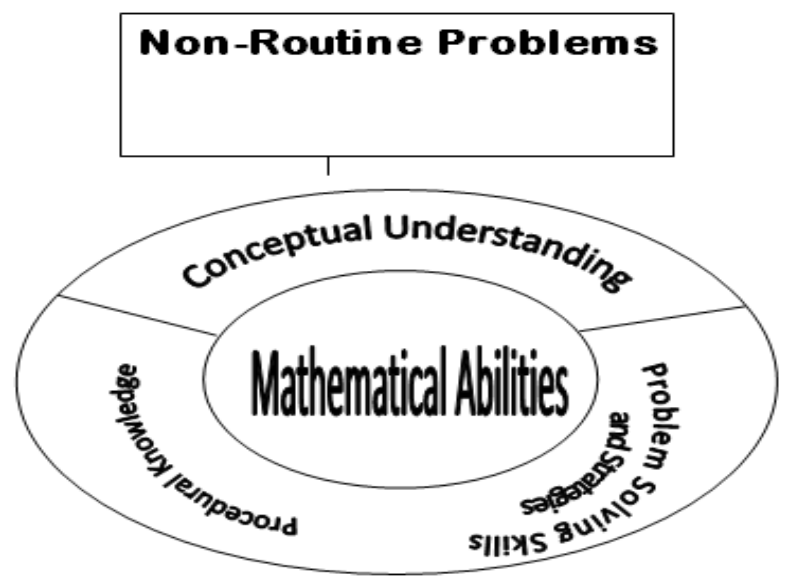

Figure 1. Conceptual Paradigm of the Study

\section{Purpose of the Research}

This study aims to determine the problem-solving heuristics and mathematical abilities of students in a National High School in the Philippines. Specifically, the study sought to answer the following questions:

1. What problem-solving heuristics do students use in solving non-routine problems when grouped according to their mathematical abilities?

2. What is the average level of mathematical abilities of the students in solving non-routine problems when grouped according to their mathematical achievement?
This research made use of descriptive design to describe and examine the problem-solving heuristics employed by the students. It utilized both quantitative and qualitative data gathered from students' mathematical solutions, journals and interviews.

\section{Participants/Respondents}

The study was conducted in a national high school in the Philippines. The researchers used stratified random sampling to choose thirty (30) participants from one hundred twenty-three (123) Grade 10 students. Each strata of mathematics achievement - above average, average, and below average, includes ten (10) students who were randomly selected using their averages in the first two quarters.

\section{Instruments Used}

\section{Non-Routine Problems}

Six non-routine problem worksheets, one for each non-routine problem, were given to each student during the three problem-solving sessions. The Problem-Solving Test used by Fortes and Andrade [2] was employed in this study.

\section{Journal Writing Notebook}

A journal-writing notebook was given to each student to reflect on his or her solutions to each problem. Guide questions were provided to give the students idea on what to reflect on.

\section{Interview Guide}

This instrument was used with all thirty (30) students and the questions include an explanation on their first impression of the problem, identifying the problems that were most difficult for them and giving clarification for their solutions.

\section{Problem Solving Rubric and Scoring Rubric}

Nine experts validated the problem solving and scoring rubrics. They are the same experts who validated the Problem Solving Test. The problem-solving rubric developed by the Oregon Department of Education [23] was adopted.

\section{Data Collection and Analysis Procedures}

On the first session, the students were asked to fill out the preliminary questionnaires where the first two non-routine problems were also given. The other remaining 4 questions were given during the second and third sessions. They were to write a journal about each problem before proceeding to the next problem. Students were interviewed individually for at least 30 minutes and the interviews were audio-taped. While solving, students were allowed to ask questions about the direction and clarifications about the problem. Each session is equivalent to three hours. Three 
mathematics professors were oriented on scoring, after which they were individually asked to analyze and score the students' solutions using the scoring rubric. When greatly varied scores were initially given, they discussed until they arrived at a consensus.

\section{Problem-solving Performance and Heuristics}

The problem-solving heuristics used by the students were classified and problem-solving mathematical abilities of the students were analyzed according to three components [22], namely:

1. Conceptual Understanding

2. Procedural Knowledge

3. Problem-solving Skills and Strategies

Conceptual Understanding refers to the ability to decipher the problem and choose suitable information to apply and complete the solution [23]. If there is conceptual understanding, then the students understand which ideas would be helpful in drawing inferences about certain problems. This is shown in absorbing concepts in a coherent whole, making connections between the problem situation, relevant information, appropriate mathematical concepts, and logical response.

Conceptual Understanding is categorized into three [23]:

1. Full Conceptual Understanding - The student uses all relevant information to solve the problem.

2. Partial Conceptual Understanding - The student extracts some of the "essence" of the problem, but is unable to use this information to solve the problem.

3. Lack of Conceptual Understanding - The student cannot absorb the needed information to solve the problem thus leading to an incorrect or unconnected solution to the problem situation.

The table shows the criteria for each category.

Table 1. Criteria for the Categories of Conceptual Understanding

\begin{tabular}{|c|c|}
\hline CATEGORIES & CRITERIA \\
\hline $\begin{array}{l}\text { Full Conceptual } \\
\text { Understanding } \\
\text { (Proficient) }\end{array}$ & $\begin{array}{l}\text { a. The student is able to transform the } \\
\text { problem into suitable mathematical } \\
\text { notations and symbols. } \\
\text { b. The student's answer shows consistency } \\
\text { with the problem situation. } \\
\text { c. The student fully absorbs and understands } \\
\text { the complete task. }\end{array}$ \\
\hline $\begin{array}{c}\text { Partial } \\
\text { Conceptual } \\
\text { Understanding } \\
\text { (Apprentice) }\end{array}$ & $\begin{array}{l}\text { a. The student is only partially able to make } \\
\text { connections between or among the } \\
\text { concepts. } \\
\text { b. The student's solution is not fully related } \\
\text { to the question. } \\
\text { c. The student understands one portion of } \\
\text { the task, but not the complete task. }\end{array}$ \\
\hline $\begin{array}{c}\text { Lack of } \\
\text { Conceptual } \\
\text { Understanding } \\
\text { (Novice) }\end{array}$ & $\begin{array}{l}\text { a. The student translates the problem into } \\
\text { inappropriate mathematical concepts. } \\
\text { b. The student's solution is incorrect. } \\
\text { c. The student does not understand the } \\
\text { concepts needed to complete the task. }\end{array}$ \\
\hline
\end{tabular}

Procedural Knowledge is the ability of the students to select and apply the most appropriate strategy to a particular solution in an accurate, efficient, and flexible way [23]. Proof is shown by the students' ability to verify, justify and modify procedures to be able to come up with the solution in a specific problem.

Procedural Knowledge is categorized into three [23], namely:

1. Full Use of Appropriate Procedures - The student uses appropriate rules and principles in rationalizing the solutions.

2. Partial Use of Appropriate Procedures - The student uses mathematical terms, principles, or procedures quite precisely and efficiently.

3. Lacks Use of Appropriate Procedures - The student uses unsuitable methods or simple manipulation of data in his/her attempted solution.

The table shows the criteria for each category.

Table 2. Criteria for the Categories of Procedural Knowledge

\begin{tabular}{|c|c|}
\hline CATEGORIES & CRITERIA \\
\hline $\begin{array}{l}\text { Full Use of } \\
\text { Appropriate } \\
\text { Procedures } \\
\text { (Proficient) }\end{array}$ & $\begin{array}{l}\text { a. The student uses appropriate } \\
\text { mathematical terms and strategies. } \\
\text { b. The student solves and verifies the } \\
\text { problem. } \\
\text { c. The student uses mathematical principles } \\
\text { and language precisely. }\end{array}$ \\
\hline $\begin{array}{l}\text { Partial Use of } \\
\text { Appropriate } \\
\text { Procedures } \\
\text { (Apprentice) }\end{array}$ & $\begin{array}{l}\text { a. The student is unable to carry out a } \\
\text { procedure completely. } \\
\text { b. The process the student uses to verify the } \\
\text { solution is incorrect. } \\
\text { c. The student uses mathematical } \\
\text { principles, procedures and language quite } \\
\text { efficiently. }\end{array}$ \\
\hline $\begin{array}{l}\text { Lacks Use of } \\
\text { Appropriate } \\
\text { Procedures } \\
\text { (Novice) }\end{array}$ & $\begin{array}{l}\text { a. The student fails to eliminate unsuitable } \\
\text { methods or solutions. } \\
\text { b. The student fails to verify the solution. } \\
\text { c. The student misuses principles or } \\
\text { translates the problem into inappropriate } \\
\text { procedures. }\end{array}$ \\
\hline
\end{tabular}

Problem-solving Skills are categorized into three [23].

Problem-solving requires the use of different skills, often in specific combinations. Students should also demonstrate problem-solving strategies with clearly focused, good reasoning that leads to a successful resolution of the problem.

1. Evidence of Thorough and Insightful Use of Skills/ Strategies - The skills show some evidence of insightful thinking to explore the problem.

2. Evidence of Routine or Partial Use of Skills/ Strategies- The skills have some focus, but clarity is limited.

3. Limited Evidence of Skills/ Strategies - The skills lack a central focus and the details are sketchy or not present.

The table shows the criteria for each category. 
Table 3. Criteria for the Categories of Problem-solving Skills/Strategies

\begin{tabular}{|c|c|c|}
\hline CATEGORIES & & CRITERIA \\
\hline \multirow{3}{*}{$\begin{array}{c}\text { Evidence } \\
\text { of Thorough use of Skills/ } \\
\text { Strategies } \\
\text { (Proficient) }\end{array}$} & a. & The student's work is clear and focused. \\
\hline & b. & $\begin{array}{l}\text { The procedures and skills in solving the problem are appropriate and demonstrate some insightful } \\
\text { thinking. }\end{array}$ \\
\hline & c. & The student gives possible extensions or generalizations to the solution or the problem. \\
\hline \multirow{3}{*}{$\begin{array}{c}\text { Evidence of Routine } \\
\text { Or } \\
\text { Partial Use of Skills/ } \\
\text { Strategies } \\
\text { (Apprentice) }\end{array}$} & a. & The student uses a strategy that is only partially necessary. The student starts the problem correctly, \\
\hline & a & $\begin{array}{l}\text { but shifts to an erroneous direction. } \\
\text { The student's strategy is not fully executed. }\end{array}$ \\
\hline & b. & The student recognizes the pattern or relationship, but expands it incorrectly. \\
\hline \multirow{3}{*}{$\begin{array}{l}\text { Limited Evidence of } \\
\text { Skills/Strategies } \\
\text { (Novice) }\end{array}$} & a. & The procedures are not presented (i.e. only the answer is written). \\
\hline & b. & Strategies have not been fully explored and executed. \\
\hline & c. & The student fails to discover unconventional/optional solutions needed to solve the problem. \\
\hline
\end{tabular}

The level of problem-solving ability that was shown by the students was categorized as Proficient, Apprentice or Novice. The table shows the point system used.

Table 4. Point System for the Level of Problem Solving Ability

\begin{tabular}{ll}
\hline Score & Description \\
\hline \multirow{3}{*}{5 points } & $\begin{array}{l}\text { Full Conceptual Understanding, Full Use of } \\
\text { Appropriate Procedures, Evidence of Thorough Use of } \\
\text { Skills and Strategies }\end{array}$ \\
\hline \multirow{3}{*}{3 points } & $\begin{array}{l}\text { Partial Conceptual Understanding, Partial Use of } \\
\text { Appropriate Procedures, Evidence of Partial Use of } \\
\text { Skills and Strategies }\end{array}$ \\
\hline \multirow{3}{*}{ point } & Lack of Conceptual Understanding, Lacks Use of \\
& Appropriate Procedures, Limited evidence Skills and \\
\hline
\end{tabular}

To analyze the learner's solution, the point system employed by Mabilangan [19] was considered. A score of 2 was given to a solution that would go beyond the criterion for a score of 1 , but would not suffice for a score of 3 . In the same way, a score of 4 was marked to a solution that would go beyond the criterion for 3 , but would not suffice for a score of 5 . A score of 0 was given to a solution that would not meet the criterion for a score of 1 . It means that the student has no attempt to answer any non-routine problem.

To determine the over-all performance of the students in the problem-solving test, the following mean intervals were used.

Table 5. Mean Intervals for the Over-all Problem-Solving Mathematical Abilities

\begin{tabular}{cc}
\hline Levels of Performance & Mean Intervals \\
\hline Proficient & $3.68-5$ \\
\hline Apprentice & $2.34-3.67$ \\
\hline Novice & $1.00-2.33$ \\
\hline
\end{tabular}

The students' problem-solving heuristics were also classified as follows:

a. Computing or Simplifying $(\mathrm{C} / \mathrm{S})$ - includes straightforward application of rules in mathematics, and correctly sequencing the operations, and using other mathematical procedures b. Using a Formula (F) - involves replacing a formula with the given values or choosing the correct formula that may be used

c. Making a model or Diagram (M/D) - includes using objects, drawings or sketches, modeling through actions, or translating the problem situation into an algebraic statement

d. Using a Tabular/Graphical Representation or Listing (TGRL) - pertains to presenting the information in a table, chart, graph, or listing the possibilities

e. Guessing, Checking, and Revising (GCR) - relates to doing and checking some trials and modifying errors if and when necessary

f. Simplifying the Situation (SS) - involves rewording the problem, using smaller values, using a more common problem situation, partitioning the problem into simpler problem situations, or working toward the back or from the final situation to the initial one

g. Eliminating (E) - includes getting rid of possible solutions based on the given data or eliminating some answers that are perceived to be incorrect

h. Looking for Patterns (LP) - finding general characteristics of the given data and applying these attributes to future cases or situations

For further analysis, ANOVA was employed to determine if there is any significant difference in the mathematical abilities of the students.

\section{Results and Discussion}

\section{Research Question 1: What problem-solving heuristics do students use in solving non-routine problems when grouped according to their mathematical abilities?}

The table shows the strategies used by the students in each problem when grouped according to the level of mathematical abilities. 
Table 6. Problem Solving Heuristics Used by the Thirty Students on Six Non-Routine Problems

\begin{tabular}{|c|c|c|c|c|c|c|}
\hline $\begin{array}{l}\text { Stud } \\
\text { No. }\end{array}$ & Problem 1 & Problem 2 & Problem 3 & Problem 4 & Problem 5 & Problem 6 \\
\hline \multicolumn{7}{|c|}{ Proficient Problem Solvers } \\
\hline 1 & $\mathrm{M} / \mathrm{D}, \mathrm{C} / \mathrm{S}, \mathrm{GCR}$ & TGRL,C/S,GCR, SS,M/D & $\mathrm{M} / \mathrm{D}, \mathrm{C} / \mathrm{S}, \mathrm{GCR}, \mathrm{TGRL}$ & $M / D, T G R L, L P, E$ & TGRL,LP,C/S, F,M/D,GCR & $\mathrm{M} / \mathrm{D}, \mathrm{GCR}, \mathrm{TGRL}, \mathrm{C} / \mathrm{S}, \mathrm{SS}$ \\
\hline 2 & $\mathrm{M} / \mathrm{D}, \mathrm{C} / \mathrm{S}, \mathrm{GCR}, \mathrm{TGRL}$ & TGRL,C/S,GCR, MD & $\mathrm{M} / \mathrm{D}, \mathrm{C} / \mathrm{S}, \mathrm{F}$ & $\mathrm{M} / \mathrm{D}, \mathrm{LP}, \mathrm{E}$ & TGRL,C/S & $\mathrm{M} / \mathrm{D}, \mathrm{GCR}, \mathrm{TGRL}, \mathrm{C} / \mathrm{S}, \mathrm{SS}$ \\
\hline 7 & $\mathrm{M} / \mathrm{D}, \mathrm{C} / \mathrm{S}, \mathrm{GCR}, \mathrm{TGRL}$ & TGRL,GCR,C/S & $M / D, C / S$ & $L P, E, M / D$ & TGRL,C/S & $\mathrm{M} / \mathrm{D}, \mathrm{GCR}, \mathrm{TGRL}, \mathrm{C} / \mathrm{S}$ \\
\hline \multicolumn{7}{|c|}{ Apprentice Problem Solvers } \\
\hline 3 & $\mathrm{C} / \mathrm{S}, \mathrm{GCR}$ & TGRL & $M / D, C / S$ & $E$ & $\mathrm{C} / \mathrm{S}$ & SS \\
\hline 4 & TGRL,C/S,GCR & GCR & $\mathrm{M} / \mathrm{D}, \mathrm{C} / \mathrm{S}$ & GCR,M/D & TGRL, GCR & SS \\
\hline 5 & $\mathrm{M} / \mathrm{D}, \mathrm{C} / \mathrm{S}, \mathrm{GCR}, \mathrm{TGRL}$ & TGRL,C/S,GCR & $\mathrm{M} / \mathrm{D}, \mathrm{C} / \mathrm{S}$ & $E, M / D$ & TGRL,M/D,C/S & SS \\
\hline 6 & $\mathrm{M} / \mathrm{D}, \mathrm{C} / \mathrm{S}$ & TGRL & $\mathrm{M} / \mathrm{D}, \mathrm{C} / \mathrm{S}$ & TGRL,GCR & TGRL,C/S & SS \\
\hline 8 & $\mathrm{c} / \mathrm{S}$ & TGRL & $\mathrm{M} / \mathrm{D}, \mathrm{C} / \mathrm{S}$ & LP & TGRL,C/S & SS \\
\hline 9 & $\mathrm{C} / \mathrm{S}, \mathrm{TGRL}$ & $\mathrm{GCR}, \mathrm{C} / \mathrm{S}$ & $M / D, C / S$ & $\mathrm{LP}$ & $\mathrm{C} / \mathrm{S}$ & SS \\
\hline 10 & $\mathrm{C} / \mathrm{S}, \mathrm{TGRL}$ & TGRL & $\mathrm{M} / \mathrm{D}, \mathrm{C} / \mathrm{S}$ & GCR & TGRL,C/S & SS \\
\hline 11 & TGRL & TGRL & $\mathrm{M} / \mathrm{D}, \mathrm{C} / \mathrm{S}$ & $\mathrm{E}$ & TGRL,C/S & SS \\
\hline 12 & $\mathrm{C} / \mathrm{S}, \mathrm{GCR}$ & TGRL,GCR & $\mathrm{M} / \mathrm{D}, \mathrm{C} / \mathrm{S}$ & $E, L P$ & $\mathrm{C} / \mathrm{S}$ & $M / D, G C R, C / S$ \\
\hline 13 & $\mathrm{C} / \mathrm{S}, \mathrm{GCR}, \mathrm{TGRL}$ & TGRL,GCR & $\mathrm{M} / \mathrm{D}, \mathrm{C} / \mathrm{S}$ & $\mathrm{LP}, \mathrm{E}$ & TGRL,C/S & SS \\
\hline 14 & $\mathrm{C} / \mathrm{S}, \mathrm{GCR}$ & TGRL & $\mathrm{M} / \mathrm{D}, \mathrm{C} / \mathrm{S}$ & $E$ & $\mathrm{C} / \mathrm{S}$ & SS,GCR,TGRL \\
\hline 15 & $\mathrm{C} / \mathrm{S}$ & TGRL & $\mathrm{M} / \mathrm{D}, \mathrm{C} / \mathrm{S}$ & GCR & $M / D$ & GCR,TGRL \\
\hline 16 & TGRL,GCR & GCR & $\mathrm{M} / \mathrm{D}, \mathrm{C} / \mathrm{S}$ & LP & TGRL,C/S & SS \\
\hline 17 & $M / D, C / S, G C R, F$ & TGRL,GCR,C/S & $\mathrm{M} / \mathrm{D}, \mathrm{C} / \mathrm{S}$ & $L P, E, M / D$ & TGRL & SS \\
\hline 18 & $\mathrm{C} / \mathrm{S}, \mathrm{GCR}$ & $\mathrm{C} / \mathrm{S}$ & $M / D, C / S$ & $E, L P$ & $\mathrm{c} / \mathrm{s}$ & SS \\
\hline 19 & $M / D, C / S, G C R$ & GCR & $M / D, C / S$ & $\mathrm{LP}$ & $M / D$ & SS \\
\hline 20 & GCR & TGRL & $\mathrm{M} / \mathrm{D}, \mathrm{C} / \mathrm{S}$ & $E, L P$ & $\mathrm{C} / \mathrm{S}$ & SS \\
\hline 21 & TGRL,C/S,GCR & TGRL & $\mathrm{M} / \mathrm{D}, \mathrm{C} / \mathrm{S}$ & $\mathrm{LP}$ & $\mathrm{C} / \mathrm{S}$ & SS,GCR \\
\hline 22 & $\mathrm{C} / \mathrm{S}$ & TGRL & $M / D, C / S$ & $\mathrm{LP}$ & TGRL & SS, TGRL, GCR \\
\hline 23 & $\mathrm{C} / \mathrm{S}, \mathrm{GCR}$ & TGRL,GCR & $\mathrm{M} / \mathrm{D}, \mathrm{C} / \mathrm{S}$ & $L P, E$ & TGRL,C/S & $\mathrm{GCR}, \mathrm{SS}$ \\
\hline 24 & $\mathrm{C} / \mathrm{S}$ & GCR & $\mathrm{M} / \mathrm{D}, \mathrm{C} / \mathrm{S}$ & GCR & $\mathrm{C} / \mathrm{S}$ & SS \\
\hline 25 & $\mathrm{C} / \mathrm{S}, \mathrm{GCR}$ & GCR & $\mathrm{C} / \mathrm{S}$ & E & $\mathrm{C} / \mathrm{S}$ & SS \\
\hline 26 & TGRL,C/S,GCR & $\mathrm{GCR}, \mathrm{C} / \mathrm{S}$ & $M / D, C / S$ & $E, L P, M / D$ & TGRL,C/S & SS \\
\hline 27 & $\mathrm{M} / \mathrm{D}, \mathrm{C} / \mathrm{S}$ & TGRL & $M / D, C / S$ & $E, L P$ & TGRL & SS \\
\hline 28 & TGRL,C/S,SS & TGRL,GCR,C/S & $M / D, C / S$ & $E, M / D$ & TGRL,M/D,C/S & SS \\
\hline 29 & $\mathrm{M} / \mathrm{D}, \mathrm{C} / \mathrm{S}, \mathrm{GCR}$ & GCR & $\mathrm{M} / \mathrm{D}, \mathrm{C} / \mathrm{S}$ & $E, M / D$ & $\mathrm{C} / \mathrm{S}$ & $\mathrm{SS}, \mathrm{GCR}$ \\
\hline 30 & TGRL,C/S,GCR & TGRL,GCR & $\mathrm{M} / \mathrm{D}, \mathrm{C} / \mathrm{S}$ & $E, L P$ & $\mathrm{M} / \mathrm{D}, \mathrm{C} / \mathrm{S}$ & SS \\
\hline
\end{tabular}

Legend:

C/S-Compute or Simplify

SS-Simplifying the Situation

M/D-Make a Model
GCR-Guess, Check, and Revise

F-Use a Formula

TGRL- Make a Table/Graphical Representation, or Listing
E-Eliminate

LP-Looking for Patterns
Table 6 presents the different heuristics used by the student-respondents in solving the six non-routine problems. As can be gleaned from the table, the student-respondents solved some of the problems by combining two or three strategies. Each respondent applied a minimum of four problem solving strategies on the six non-routine problems. This shows that if students are aware of the various problem-solving heuristics and strategies, the probability of looking for an appropriate solution increases. This is in consonant to the findings of Barham [27] that one of the factors that contributes to the success of problem solving is through problem lessons of heuristics.

Proficient Problem Solvers used the same strategy on a problem but differed in techniques. These are Student 1,
Student 2, and Student 7 who employed M/D, GCR, and $\mathrm{C} / \mathrm{S}$ in problem number 1 but varied in the way they applied the strategy as shown in their worksheets. All Proficient Problem Solvers used at least three strategies in solving problems 1,2 , and 6 . This is aligned to the findings of Fortes and Andrade [2] that skillful problem solvers can exhibit their own original solutions and strategies. On the other hand, all Apprentice Problem Solvers used M/D and $\mathrm{C} / \mathrm{S}$ to solve problem number 3 except for Student number 25 who used C/S only. Notably, M/D is the most common used strategy for Problem 3. This is similar to the findings of Yew and Zamri [28] in their study on the problem-solving strategies of pre-service secondary school mathematics teachers that drawing a diagram is the most employed strategy. 
Table 7. Frequency of Problem-Solving Heuristics Used by Students According to the Level of Mathematical Abilities

\begin{tabular}{|c|c|c|c|c|c|c|c|}
\hline \multirow{3}{*}{ Problem Solving Heuristics } & \multicolumn{6}{|c|}{ Level of Mathematical Abilities } & \multirow{3}{*}{ Tota } \\
\hline & \multicolumn{2}{|c|}{ Proficient } & \multicolumn{2}{|c|}{ Apprentice } & \multicolumn{2}{|c|}{ Novice } & \\
\hline & $\mathrm{f}$ & $\%$ & $\mathrm{f}$ & $\%$ & $\mathrm{f}$ & $\%$ & \\
\hline Compute or Simplify (C/S) & 15 & 16 & 79 & 84 & - & - & 94 \\
\hline Formula $(\mathrm{F})$ & 2 & 67 & 1 & 33 & - & - & 3 \\
\hline Model or Diagram (M/D) & 15 & 25 & 44 & 75 & - & - & 59 \\
\hline $\begin{array}{l}\text { Tabular/Graphical Representation or } \\
\text { Listing (TGRL) }\end{array}$ & 13 & 22 & 47 & 78 & - & - & 60 \\
\hline Guess, Check, or Revise (GCR) & 11 & 20 & 45 & 80 & - & - & 56 \\
\hline Simplifying the Situation (SS) & 3 & 10 & 26 & 90 & - & - & 29 \\
\hline Elimination (E) & 3 & 16 & 16 & 84 & - & - & 19 \\
\hline Looking for Patterns (LP) & 4 & 21 & 15 & 79 & - & - & 19 \\
\hline
\end{tabular}

Table 7 summarizes the problem-solving heuristics used by the students in answering the problem- solving test. The most commonly used strategy, Compute or Simplify (C/S), was employed 94 times in total. This dominance of $\mathrm{C} / \mathrm{S}$ as a strategy was also found by Villareal [20]. It is followed by TGRL (60 times), M/D (59 times), GCR (56 times), SS (29 times), LP (19 times), E (19 times) and the least used is F (3 times). It is apparent that all strategies were considered in solving the six non-routine problems. This confirms the study of Almeida and Bruno [29] that students' approach and use of strategies vary depending on the type of problems.

It can be noticed that the most frequently used strategies by proficient problem solvers were $\mathrm{C} / \mathrm{S}$ and $\mathrm{M} / \mathrm{D}$. The first strategy includes straightforward application of rules in mathematics, correctly sequencing the operations, and using other mathematical procedures, while the second includes using objects, drawings or sketches, modeling through actions, or translating the problem situation into an algebraic statement. On the other hand, the most commonly used strategy by apprentice problem solvers is also $\mathrm{C} / \mathrm{S}$ followed by TGRL. The least used strategy by the students under these two levels is using a formula. One factor to consider is that the problems given are not only solvable by using just one solution. Problem-solving and mathematical abilities of students are enhanced if they are exposed to varied problems that demand heuristics [30].

\section{On Proficient Problem Solvers}

Figure 2 shows how Student 2 used 5 problem solving heuristics in solving Problem 6.

It is worthwhile to note that Student 2 used (1) GCR strategy in solving Problem 6. She thought of possible numbers that would satisfy what was asked in the problem. She tried different numbers such as 45 and 28 until such time that she was able to use 48 . The second strategy that was used is using linear equation in three variables. This strategy falls under (2) M/D. She used variables $x, y$ and $z$ in her equation to represent $(\mathrm{x})$ the number of stickers that
Quen had at first, (y) the number of stickers remained to Quen after he had given stickers to his brother and (z) the number of stickers remained to Quen after he had given stickers to his sister. She was able to get the correct answer, 48, after applying different mathematical operations. Aside from the two strategies mentioned above, she also employed considering a (3) SS such as working backwards. SS strategy includes rewording the problem, using smaller values, using a more common problem situation, partitioning the problem into simpler problem situations, or working toward the back or from the final situation to the initial one. By applying (4) $\mathrm{C} / \mathrm{S}$, Student 2 was able to complete the task by starting her computation from 5 going to the desired number 48. After using the said strategy, Student 2 applied using a (5) TGRL. She was able to complete the table using 39 and 48 as her starting numbers but because she was able to get the answer using the previously stated strategies, she was very sure that 48 would be the correct answer. This is just one of her solutions which proved that she is a proficient problem solver, and notably, she belongs to above average level of mathematical achievement. This is consonant to the study of Yazgan [17] that high achievers have the higher percentage of success in problem-solving and executing several strategies.

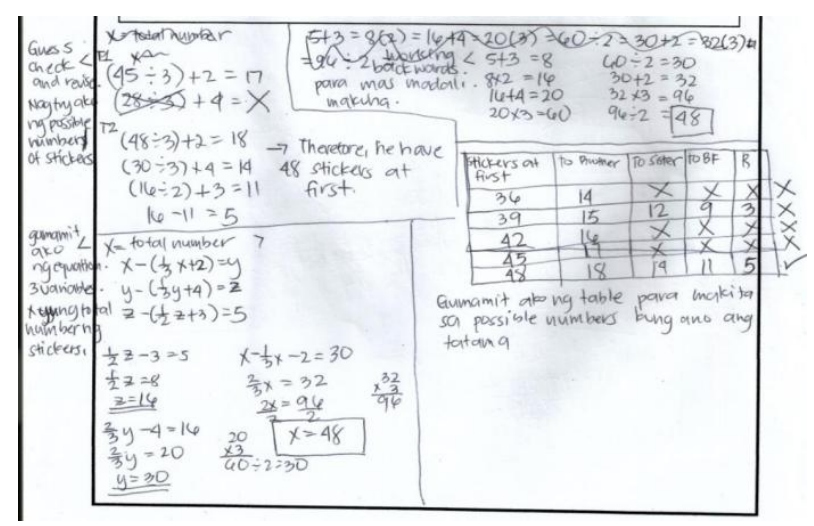

Figure 2. Problem solving Heuristics of Student 2 in Problem 6 


\section{On Apprentice Problem Solvers}

All students under this group used $\mathrm{M} / \mathrm{D}$ and $\mathrm{C} / \mathrm{S}$ in answering Problem No. 3. An example of this solution was shown by Student 22. It can be seen in her solution that she drew six squares with a side equivalent to 20 . She also computed for the greatest common factor of 40 and 60 then multiplied the quotient getting the number of squares which is 6 . Student 22 was able to show how she arrived in getting six biggest possible squares. This result confirms the study of Al-Balasi and Barham [31] that the students can employ a wide variety of mathematical representations enhancing their problem-solving mathematical abilities. Her solution is shown in the next figure.

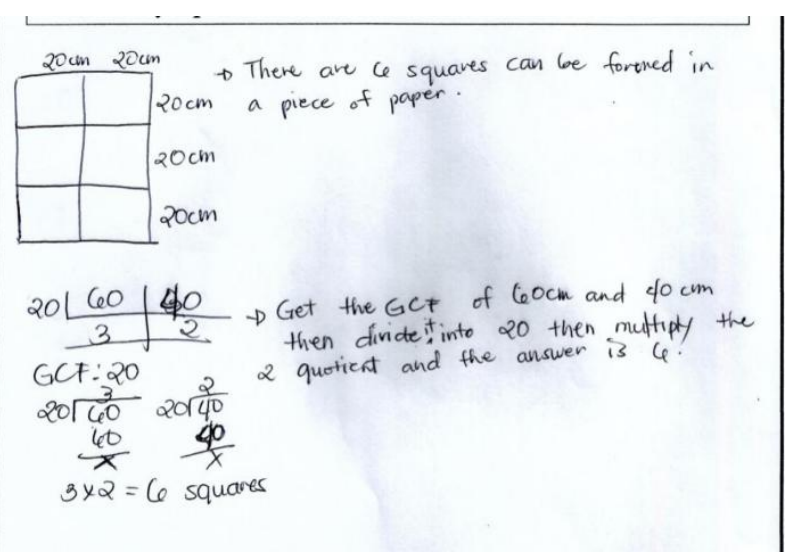

Figure 4. Solution of Student 22 in Problem 3

\section{Research Question 2: What is the average level of mathematical abilities of the students in solving non-routine problems?}

Table 8 shows that three of the ten above average students are proficient problem solvers. They are Students 1, 2 and 7. They all got an over-all mean greater than 3.67 while the rest of the students were apprentice problem solvers and got an over-all mean greater than 2.33 but less than 3.68. Apparently, the three proficient problem solvers are successful in all three components since they were focused on developing their own method for themselves based from the qualities of the problem. According to Maulana and Yuniawati [32], student with high - ability was able to do well in solving non-routine problems by understanding the task and looking back the results. The over-all mean of the ten above average students on the three components; conceptual understanding, procedural knowledge, and problem-solving skills/strategies is 3.70 which is proficient in general. All students got a high over-all mean which is 4.2 on conceptual understanding while lowest on problem solving skills which is 3.3. Some students were able to understand which ideas would be helpful in drawing inferences about certain problems and making connections to form a coherent whole. They were also able to use this interpretation and understanding to select the most appropriate strategy to the six non-routine problems resulting to a clear and focused solution. Students had shown the ability to justify and verify their solution in most non-routine problems. On the other hand, there were some students who were able to carry out the procedure quite precisely because they overlooked some concepts needed and failed to eliminate unsuitable solution. But, over-all, they understood the problem and were able to translate the problem into mathematical language and exhibit insightful thinking. In general, these students demonstrated good problem-solving abilities.

Table 8. The Problem-Solving Mathematical Abilities of Above Average Students

\begin{tabular}{cccccc}
\hline \multirow{2}{*}{ Stud No. } & \multicolumn{2}{c}{ Mean of Above Average Students } & & \multicolumn{2}{c}{$\begin{array}{c}\text { Level of } \\
\text { Mathematical } \\
\text { Abilities }\end{array}$} \\
\cline { 2 - 5 } & $\begin{array}{c}\text { Conceptual } \\
\text { Understanding }\end{array}$ & $\begin{array}{c}\text { Procedural } \\
\text { Knowledge }\end{array}$ & $\begin{array}{c}\text { Problem Solving } \\
\text { Skills/ Strategies }\end{array}$ & Over-All Mean & Proficient \\
2 & 5 & 5 & 4 & 4.67 & Proficient \\
3 & 5 & 5 & 4 & 4.67 & Apprentice \\
4 & 4 & 3 & 3 & 3.67 & Apprentice \\
5 & 4 & 4 & 3 & 3.33 & Apprentice \\
6 & 4 & 3 & 3.33 & Apprentice \\
7 & 4 & 3 & 4.00 & Proficient \\
8 & 4 & 4 & 3 & 3.00 & Apprentice \\
9 & 3 & 3 & 3 & 3.33 & Apprentice \\
10 & 4 & 3 & 3 & 3.67 & Apprentice \\
\hline Over-all Mean & 5 & 3 & 3.3 & 3.70 & PROFICIENT \\
\hline
\end{tabular}


Table 9. The Problem-Solving Mathematical Abilities of Average Students

\begin{tabular}{|c|c|c|c|c|c|}
\hline \multirow[b]{2}{*}{ Stud No. } & \multicolumn{3}{|c|}{ Mean of Average Students } & \multirow[b]{2}{*}{ Over-All Mean } & \multirow{2}{*}{$\begin{array}{c}\text { Level of } \\
\text { Mathematical } \\
\text { Abilities }\end{array}$} \\
\hline & $\begin{array}{c}\text { Conceptual } \\
\text { Understanding }\end{array}$ & $\begin{array}{c}\text { Procedural } \\
\text { Knowledge } \\
\end{array}$ & $\begin{array}{l}\text { Problem Solving } \\
\text { Skills/ Strategies } \\
\end{array}$ & & \\
\hline 11 & 4 & 3 & 3 & 3.33 & Apprentice \\
\hline 12 & 4 & 4 & 3 & 3.67 & Apprentice \\
\hline 13 & 4 & 4 & 3 & 3.67 & Apprentice \\
\hline 14 & 4 & 4 & 3 & 3.67 & Apprentice \\
\hline 15 & 3 & 3 & 2 & 2.67 & Apprentice \\
\hline 16 & 4 & 3 & 3 & 3.33 & Apprentice \\
\hline 17 & 5 & 3 & 3 & 3.67 & Apprentice \\
\hline 18 & 4 & 3 & 3 & 3.33 & Apprentice \\
\hline 19 & 3 & 4 & 3 & 3.33 & Apprentice \\
\hline 20 & 3 & 3 & 2 & 2.67 & Apprentice \\
\hline Over-all Mean & 3.8 & 3.4 & 2.8 & 3.33 & APPRENTICE \\
\hline
\end{tabular}

Table 10. The Problem-Solving Mathematical Abilities of Below Average Students

\begin{tabular}{|c|c|c|c|c|c|}
\hline \multirow[b]{2}{*}{ Stud No. } & \multicolumn{3}{|c|}{ Mean of Below Average Students } & \multirow[b]{2}{*}{ Over-All Mean } & \multirow{2}{*}{$\begin{array}{c}\text { Level of } \\
\text { Mathematical } \\
\text { Abilities }\end{array}$} \\
\hline & $\begin{array}{c}\text { Conceptual } \\
\text { Understanding }\end{array}$ & $\begin{array}{l}\text { Procedural } \\
\text { Knowledge }\end{array}$ & $\begin{array}{l}\text { Problem Solving } \\
\text { Skills/ Strategies }\end{array}$ & & \\
\hline 21 & 3 & 3 & 3 & 3.00 & Apprentice \\
\hline 22 & 4 & 3 & 2 & 3.00 & Apprentice \\
\hline 23 & 4 & 2 & 3 & 3.00 & Apprentice \\
\hline 24 & 3 & 3 & 3 & 3.00 & Apprentice \\
\hline 25 & 2 & 3 & 2 & 2.33 & Apprentice \\
\hline 26 & 4 & 4 & 3 & 3.67 & Apprentice \\
\hline 27 & 4 & 3 & 2 & 3.00 & Apprentice \\
\hline 28 & 4 & 4 & 3 & 3.67 & Apprentice \\
\hline 29 & 4 & 3 & 3 & 3.33 & Apprentice \\
\hline 30 & 3 & 4 & 4 & 3.67 & Apprentice \\
\hline Over-all Mean & 3.5 & 3.2 & 2.8 & 3.17 & APPRENTICE \\
\hline
\end{tabular}

Table 9 shows that all ten average students are all apprentice problem solvers with an over-all mean greater than 2.33 but less than 3.68. They are only partially able to make connections, thus, recognize only portion of the task. The processes used by the students to verify the solution is incorrect. Further, the students translated the problems into suitable mathematical language fairly. The over-all mean of the ten average students on the three components; conceptual understanding, procedural knowledge, and problem-solving skills/strategies is 3.33 which is also apprentice in general. Similar to the above average students, all average students got a high over-all mean on conceptual understanding which is 3.8 while lowest on problem solving skills with an over-all mean of 2.8 .

Table 10 shows that all ten below average students are all also apprentice problem solvers with an over-all mean greater than 2.33 but less than 3.68. The over-all mean of the ten below average students on the three components; conceptual understanding, procedural knowledge, and problem-solving skills/strategies is 3.17 which is also apprentice in general. Similar to the two groups of students, all below average students got a high score on conceptual understanding while lowest on problem solving skills.

The over-all problem-solving mathematical abilities of the 30 selected students in terms of conceptual understanding, procedural knowledge and problem-solving skills were determined. The level of performance of the students in each component varied. The level of expertise in the problem-solving test was also categorized as proficient and apprentice and no student was classified as Novice. It is shown in the table that students performed best in conceptual understanding and least in problem solving skills and strategies in each level of mathematical performance. This contradicts that students performed least in conceptual understanding [18]. However, this supports the findings of Lev and Leikin [33] that verifying the answer through the use of several strategies is of "gift type".

It can also be deduced from the table that above-average students in general are considered as proficient problem solvers. However, only 3 out of 10 are only identified as proficient problem solvers. Exposure and participation to several contests and trainings seem to contribute to problem solving mathematical ability of these 3 students. 
This affirms the study of Lester [34] that previous experiences and robust mathematical foundation accord to complete success in problem solving. Meanwhile, the students belonging to average level of mathematical achievement are all considered as apprentice problem solvers. This finding is relevant to Chiu [35] that mathematical performance is linked to problem-solving ability. Surprisingly, all below average students fall under apprentice level. It can be viewed that the students understand the concepts and ideas but they lack the knowledge of different heuristics [30]. This confirms the study of Mogari and Chirove [11] that problem-solving lessons to different heuristics improve the mathematical ability of the students. Further, it also shows that the potential of arriving at the correct answer escalates if students are given the chance to use the strategy they prefer.

\section{On Proficient Problem Solvers}

A proficient problem solver can transform the problem into suitable mathematical notations and symbols and one who fully understands the complete task. The student also uses appropriate rules and principles in rationalizing the solutions. The student's work can be described as clear and focused, thus the procedures and skills in solving the problem are appropriate and demonstrate some insightful thinking.

A work that illustrates from above average level is the solution of Student 7 in Problem 6 as shown in Figure 5.

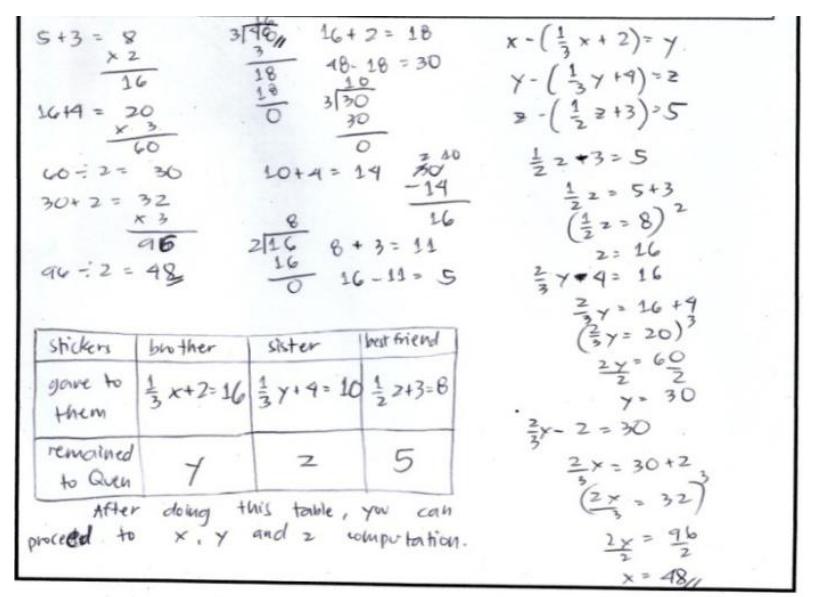

Figure 5. Solution of Student 7 in Problem 6

It can be seen in the figure that Student 7 thoroughly investigated the situation and used all needed information to solve the problem. She was able to use working backwards and linear equation effectively towards getting the right answer, which is 48 stickers. It can be seen in the detailed computation that she applied different methods on how to verify her answer. She was able to justify her solution by applying different strategies that explained well during the interview. All these make her a proficient problem solver.

\section{On Apprentice Problem Solvers}

An Apprentice Problem Solver can extract the information given in the problem, but fails to relate this information to what are necessary to unlock the problem. The solver could only partially see the interconnectedness of the concepts involved; or the student's solution somewhat deviates from what is asked in the problem; or the student understands just some but not the complete portion of the task. In terms of procedural knowledge, apprentice problem solver is not precise in using mathematical terms, principles or procedures leading to the partial use of appropriate procedures. This implies that an Apprentice Problem Solver is unable to carry out a procedure completely and one who applies appropriate initial steps but shifts to an erroneous direction afterwards. Majority of the students were perceived as apprentice problem solvers. This result is in accord to Apostol [13] that most of the students were classified as Apprentice in solving non-routine problems in terms of heuristics.

The solution of an Apprentice Problem Solver can be seen in the next figure.

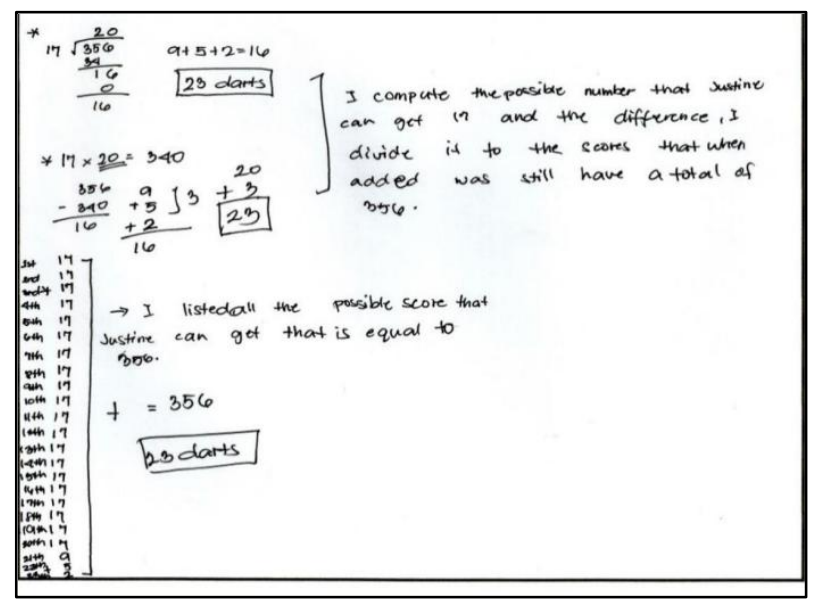

Figure 6. Solution of Student 6 in Problem 1

It may be seen in the solution as presented in Figure 6 that Student 6 understands the problem very well. She is able to use some relevant information to answer the problem. Her solution is consistent by applying two strategies efficiently. She was able to justify and verify her solution by listing all the possibilities of getting the correct answer as she wrote "I listed all the possible score that Justine can get that is equal to 356.". This confirms the claims of Charlesworth [36] that achieving conceptual understanding is an important component of mathematics education. In addition, procedural skills should be accompanied by some form of understanding so that insightful thinking and better learning can be achieved [18].

For further analysis, ANOVA was employed to determine if there is any significant difference in the mathematical abilities of the students when they are grouped according to mathematical achievement. Table 11 shows a summary of the results. 
Table 11. Summary of ANOVA on the Mean Differences of the above Average, Average and Below Average Students

\begin{tabular}{cccccccc}
\hline & & $\begin{array}{c}\text { Sum of } \\
\text { Squares }\end{array}$ & df & Mean Square & F & Sig. & Interpretation \\
\hline \multirow{2}{*}{ Conceptual } & Between Groups & 2.467 & 2 & 1.233 & 2.846 & 0.076 & Not Significant \\
Understanding & Within Groups & 11.7 & 27 & 0.433 & & & \\
& Total & 14.167 & 29 & & & & Not Significant \\
Procedural & Between Groups & 0.8 & 2 & 0.4 & 0.871 & 0.43 & \\
Knowledge & Within Groups & 12.4 & 27 & 0.459 & & & Not Significant \\
& Total & 13.2 & 29 & & & \\
\hline
\end{tabular}

The results revealed that there are no significant differences in the levels of each of the three components of mathematical abilities of students when they are grouped according to mathematical achievement. These results seem to imply that the levels of conceptual understanding of above average, average and below average students are comparable. This holds true in terms of the levels of procedural knowledge and problem solving skills of the three groups. The non-significant differences in their mathematical abilities may be attributed to the minimal number of students who were categorized differently from among the rest of students belonging to the 3 groups. Though in general, the level of mathematical abilities of the above average students is proficient while the levels of both average and below average students are apprentice, it is worthwhile to note that only 3 students in the above average group belong to the proficient level while the rest of 27 students ( 7 above average, 10 average and 10 below average) belong to the apprentice level. Their high performance seems to contribute minimally to the performance of the above average group. However, it is also worthy to recall that the proficient problem solvers used at least 3 strategies in solving the 6 non-routine problems while the rest used either 1 or 2 strategies in solving most of those problems. Also, the approaches used by the proficient problem solvers in employing the strategies are notably different from those used by the rest of the students. This seemingly implies that though the levels of mathematical abilities of the 3 groups of students do not differ significantly, the proficient problem solvers who belong to the above average group employ a wide variety of problem solving heuristics and approaches that could apparently enhance their conceptual understanding, procedural knowledge and problem solving skills.

\section{Implication to teaching}

It was observed that Students 1, 2 and 7 are proficient problem solvers. They exceeded the other respondents in terms of mathematical abilities because of using different strategies in solving non-routine problems. Exposure to trainings and several contests become a great advantage in solving non-routine problems.

Throughout the study sessions, students expressed their excitement and fun in solving non-routine problems. It was a common idea in their journals that the problems included in the problems solving test stimulated their interest. They even stated that they were encouraged to find the answer especially if they were given the chance to think of unique ways on how to solve it. Fortes and Andrade [2] stressed that teachers and students of mathematics should pay more attention to non-routine problem solving because such can largely improve mathematical instruction. In addition, students' genuine development of problem-solving skills can only happen through practicing non-routine problems [30]. This is important because learning non-routine problem-solving strategies can help individuals solve problems in unfamiliar topic areas and expand their point of view [17]. It can be observed that providing students with a framework for the use of strategies is beneficial in increasing students' level of confidence [11]. Inclusion of non-routine problems in textbook will be very helpful in attaining these goals. This supports the observations of several authorities that only a very small proportion of the problems included in the textbooks and classroom discussion is non-routine [36-40]. In some textbooks series, these problems are completely absent. In addition, Elia et al, [41] and Yazgan [17] suggested that problem-based curriculum could be more effective than the conventional content-rich curriculum in developing two most important thinking skills of students namely, critical and analytical. Some of the topics in math lessons have to be intertwined in problem solving to give better results in students' learning.

Each student used at least four problem-solving heuristics in answering the problem situations that are all non-routine. A problem-solving heuristic can be applied by a student in varied ways based on the nature of the problem. The results show that students typically use the same strategy in different approaches [11,41]. This study also debunks the social stereotyping that non-routine problems only work best among highly-intelligent learners, leaving 
the average and below average learners behind. By using problem heuristics, most students are able to find alternative solutions when they fail to get the correct answer using the initial strategy. Besides, they exhausted all possible scenarios to verify their answers. Mogari and Chirove[11] and Tan [30] suggested that non-routine problems must be part of daily discussion. They further added that exposure to non-routine problem-solving answers the call to the demands of future workforce.

\section{Conclusions and Recommendations}

Compute or Simplify is the most frequent strategy used by the students across mathematical achievement. Students could use more than one strategy if the classroom environment permits them to do so. By employing these heuristics, students could verify if the initial answer is correct or not. It only reveals that non-routine problem solving develops their problem-solving ability.

Non-routine problems are not only for high ability students but for average and below average students as well. Therefore, students attending regular schools can solve non-routine problems successfully, if they will be given appropriate interventions and problem-solving lessons on heuristics. Students from a national high school can somehow provide original solutions in solving non-routine problems. Moreover, students are motivated to solve problems that do not require them to use a fixed procedure. Students who are exposed to different training sessions and contests seem to have the bigger potential in attaining the highest level of problem-solving performance. They are also the students who could exhibit various problem-solving heuristics in solving non-routine problems.

Further, some ideas that are not shown in the student's solutions could be revealed and clarified in the journal entries and interviews. These instruments used together can provide thorough and balanced assessments of students' learning.

The inclusion of non-routine problems in the mathematics curriculum materials will require teachers to include such in mathematics classes. This is highly recommended because solving non-routine problems could develop and enhance the problem-solving performance of students. Exposure to non-routine problems could start during grade 1 level. Consequently, teachers must be given enough training and seminar on non-routine problems so that they can teach it to their students well. Likewise, students should be exposed to different strategies so that they can try other ways if the previously used strategy failed. This would make Mathematics fun and interesting for them because they can plan and invent their own solutions. Teachers should not focus on using only one solution, but instead must be open-minded in encouraging students to find their own solutions. Lastly, it is also recommended that a similar study be done to pre-service and in-service teachers with a larger number of participants to examine their heuristics and mathematical ability. A comparison of problem-solving heuristics and mathematical ability of students in regular and high-performing schools may also be done.

\section{REFERENCES}

[1] The World Economic Forum, Global Challenge Insight Report. (2016). The Future of Jobs: Employment, Skills and Workforce Strategy for the Fourth Industrial Revolution. Available online at: http://www3.weforum.org/doC/S/ WEF_Future_of_Jobs.pd understanding problem. Hacettepe University Education Faculty Journal,38, 11-24.

[2] Fortes, E.C., \& Andrade, R.R. (2019). Mathematical Creativity in Solving Non-Routine Problems. The Normal Lights, 13(1), $108-135$.

[3] Voogt J. and Roblin N. P (2010) 21st Century Skills: Discussion Paper (Netherlands: Universiteit Twente)

[4] Rakhmawati, I \&Budiyono, B. \& Saputro, Dewi. (2019). An analysis of problem solving ability among high school students in solving linear equation system word problems. Journal of PhysiC/S: Conference Series. 1211. 012098. 10.1088/1742-6596/1211/1/012098.

[5] M/D, M. R. (2019). 21st Century Skill "Problem Solving": Defining the Concept. Asian Journal of Interdisciplinary Research, 2(1), 64-74. https://doi.org/10.34256/ajir1917

[6] Scherer, R., \& Gustafsson, J. (2015). The Relations among Openness, Perseverance, and Performance in Creative Problem Solving: A Substantive-Methodological Approach. Thinking Skills and Creativity, 18, p.4-17, December 2015.

[7] Organisation for Economic Co-operation and Development. (2013). Education at a glance 2013. Retrieved from http://www.oecd.org/edu/eag2013\%20 (eng)--FINAL\%2020\%20June\%202013.pdf

[8] OECD (2019), PISA 2018 Results (Volume I): What Students Know and Can Do, PISA, OECD Publishing, Paris, https://doi.org/10.1787/5f07c754-en

[9] OECD (2019), PISA 2018 Results (Volume II): Where All Students Can Succeed, PISA, OECD Publishing, Paris, https://doi.org/10.1787/b5fd1b8f-en

[10] OECD (2019), PISA 2018 Results (Volume III): What School Life Means for Students' Lives, PISA, OECD Publishing, Paris, https://doi.org/10.1787/acd78851-en

[11] Mogari, David \&Chirove, Munyaradzi. (2017). Comparing grades 10-12 mathematics learners' non-routine problem solving. Eurasia Journal of Mathematics, Science and Technology Education. 13. 4523-4551. 10.12973/eurasia.2 017.00946a.

[12] Laset, L.B. and Limjap A.A. (2005). An Exploratory Investigation of the Problem-Solving Heuristics of High Performing Senior Students. Intersection. Published by the PCMTE (MATHED). 
[13] Apostol, E. M. D. (2017). Problem Solving Heuristics on Non-Routine Problems of College Students. American Journal of Educational Research, 5(3), 338-343.

[14] KheM/Duth Singh, Angateeah. (2017). An Investigation of Students' Difficulties in Solving Non-Routine Word Problem at Lower Secondary. International Journal of Learning and Teaching. 46-50. 10.18178/ijlt.3.1.46-50.

[15] Webb, N.L. (2010). Content complexity and depth-of-knowledge as applicable to research and practice. In D. Mogari; A. Mji; F. Mundalamo \& U.I. Ogbonnaya (eds). Proceedings of ISTE2010 International Conference: Towards Effective Teaching and Meaningful Learning in MST, pp. $1-19$

[16] Mogari, D., \&Lupahla, N. (2013). Mapping a group of Northern Namibian grade 12 learners' algebraic non-routine problem solving skills. African Journal of Research in Mathematics, Science and Technology Education, 17(1/2), 94-105.

[17] Yazgan, Y. (2015). Sixth graders and non-routine problems: Which strategies are decisive for success?. Academic Journals. Educational Research and Reviews. Vol. 10(13), pp.1807-1816. Retrieved March 28, 2019 from http://www.academicjournals.org/ERR.

[18] Masooma Ali Al-Mutawah \& Ruby Thomas \& Abdulla Eid \&Enaz Yousef Mahmoud \& Moosa Jaafar Fateel, 2019. "Conceptual Understanding, Procedural Knowledge and Problem-Solving Skills in Mathematics: High School Graduates Work Analysis and Standpoints," International Journal of Education and Practice, Conscientia Beam, vol. 7(3), pages 258-273.

[19] Mabilangan, R. A., Limjap, A. A., \& Belecina, R. R. (2011). Problem solving strategies of high school students on non-routine problems: A case study. Alipato: A Journal of Basic Education, 5, 23-46.

[20] Villareal, I. (2014). Heuristics in Solving Nonroutine Problems of Selected Students in a City Science High School. Philippine Normal University.

[21] National Research Council. (2001). Adding It Up: Helping Children Learn Mathematics. National Academy Press.

[22] National Council of Teachers of Mathematics.(2000). Principles and standards for school mathematics. Reston, VA: Author

[23] Oregon Department of Education. (1991). Oregon Mathematics Problem Solving Rubric.

[24] Polya G. (1945). How to solve it? (1 $1^{\text {st }}$ ed.) Princeton, New Jersey: Princeton University Press.

[25] New Zealand Math Ministry of Education. (2002). Problem Solving Strategies. Retrieved January 28, 2020 from http://www.nzmaths.co.nz/PS/Info/PSStrategies.htm 123

[26] Krulik, S. \& Rudnick, J.A. (1996). The New Sourcebook for Teaching Reasoning and Problem Solving in Junior and Senior High Schools. Boston, MA: Allyn and Bacon.

[27] Barham, A. I. (2020). Investigating the development of pre-service teachers' problem-solving strategies via problem-solving mathematics classes. European Journal of Educational Research, 9(1), 129-141. https://doi.org/10.12973/eujer.9.1.129

[28] Yew, W. T., \& Zamri, S. N. (2016). Problem solving strategies of selected pre-service secondary school mathematics teachers in Malaysia. The Malaysian Online Journal of Educational Sciences, 4(2), 17-3

[29] Almeida, R., \& Bruno, A. (2014). Strategies of pre-service primary school teachers for solving addition problems with negative numbers. International Journal of Mathematical Education in Science and Technology, 45(5), 719-737.

[30] Tan, D. A. (2018). Mathematical problem solving heuristics and solution strategies of senior high school students. International Journal of English and Education, 7(3), 1-17.

[31] Al-Balasi, R. I., \& Barham, A. I. (2010). The effect of using multiple mathematical representations on the attainment of mathematical concepts among basic eighth grade students and their ability to solve verbal problems. Dirasat: Educational Sciences, 37(1), 1-13.

[32] Maulana F., Yuniawati N (2018) International Journal of Information and Education Technology, Vol. 8, No. 9, September 2018. Retrieved on September 2018 from https://www.researchgate.net/publication/325969122 Stude nts'_Problem_Solving_Ability_in_Non-routine_Geometry_ Problem

[33] Lev, M., \& Leikin, R. (2013). The connection between mathematical creativity and high ability in a mathematics. University of Haifa. Retrieved from http://www.scholar.googleusercontent.com/.

[34] Lester, F. K. (2013). Thoughts about research on mathematical problem-solving instruction. The Mathematics Enthusiast, 10(1/2), 245-278.

[35] Chiu, M.-S. (2009). Approaches to the teaching of creative and non-creative mathematical problems. International Journal of Science and Mathematics Education, 7, 55-79.

[36] Charlesworth, R., 2012. Experiences in math for young children. Belmont, CA: Wadsworth Cengage Learning.

[37] Kolovou, A., van den Heuvel-Panhuizen, M., Bakker, A. (2009). Non-routine problem-solving tasks in primary school mathematics textbooks - a needle in a haystack. Mediterranean J. Res. Math. Educ. 8(2):31- 68.

[38] AMESA (2013). A report on the 2013 Mathematics \& Mathematical Literacy Grade 12 Examination Papers. Retrieved from www.amesa.org.za on 2014/07/31.

[39] Department of Basic Education (2014). Report on the annual national assessments of 2014: Grade 1-6 \& 9. Pretoria: Government Press.

[40] Marchiş, I. (2012). Non-Routine Problems in Primary Mathematics Workbooks from Romania.

[41] Elia, I., Van den Heuvel-Panhuizen, M., \&Kolovou, A. (2009). Exploring strategy use and strategy flexibility in non-routine problem solving by primary school high achievers in mathematics. Zdm Mathematics Education, 41: 605-618. 